\title{
Objectivism and Perspectivism about The Epistemic Ought
}

\author{
CONOR MCHUGH AND JONATHAN WAY \\ University of Southampton
}

W

HAT ought you believe? According to a traditional view, it depends on your evidence: you ought to believe (only) what your evidence supports. Recently, however, some have claimed that what you ought to believe depends not on your evidence but simply on what is true: you ought to believe (only) the truth. This disagreement parallels one in ethics, between so-called perspectivists and objectivists. Perspectivists in ethics hold that how you ought to act depends on your epistemic position, whereas objectivists hold that it depends on all the facts, regardless of your epistemic position with respect to them. The view that what you ought to believe depends on your evidence can be thought of as a version of perspectivism about the epistemic ought; the view that what you ought to believe depends only on what is true can be thought of as a version of objectivism about the epistemic ought. ${ }^{1}$

This debate is of intrinsic interest for epistemology-indeed, some philosophers take 'what ought I believe?' to be the central question of epistemology (Berker 2013). And it is of broader significance, given the ways in which questions about what you ought to believe connect to questions about rationality, justification, reasons for belief, and knowledge. Furthermore, as we will argue, the debate has implications for the nature of doxastic deliberation, and for the parallel debate between objectivists and perspectivists in ethics.

In this paper we present two arguments against objectivism about the epistemic ought. We argue that both raise serious problems for objectivism. In the final section we discuss some implications of our arguments, including some problems for objectivism about the practical ought. We start, however, by clarifying the disagreement between objectivism and perspectivism.

1. For convenience, we use the noun phrase 'the ought', or 'the epistemic ought', to refer to the property picked out by relevant uses of 'ought' as a verb in sentences of the form 'S ought to $\phi$ '.

Contact: Conor McHugh <c.mchugh@soton.ac.uk> and Jonathan Way <j.way@soton.ac.uk> 


\section{The Question}

The debate between objectivists and perspectivists in ethics can be illustrated with the following example (Kiesewetter 2011):

DостоR: A patient has a treatable disease. If left untreated it will lead to death. All of the doctor's evidence indicates that drug A will cure her patient and drug B will kill her. In fact, drug A will kill the patient and drug B will cure her.

How ought the doctor act? Some will think that she ought to prescribe drug B, since that will in fact cure her patient. Others will think that since her evidence indicates that drug A will cure her patient, she ought to give A. This disagreement stems from disagreement about whether one's epistemic position bears on what one ought to do. Roughly, perspectivists about the practical ought hold that it does; objectivists hold that it does not.

There are different ways to make this debate more precise. One issue concerns what counts as one's epistemic position. Natural candidates include one's knowledge, what one is in a position to know, one's evidence, what one reasonably believes, and one's non-factive mental states. A further issue is how to understand the notion of dependence. One approach takes perspectivists to endorse a supervenience thesis: no difference in what one ought to do without a difference in epistemic position. Objectivists can then be taken to deny all versions of this thesis (that is, however one's epistemic position is understood). Alternatively, perspectivism might be understood as the view that only considerations which are epistemically accessible to an agent can be reasons bearing on what that agent ought to do, with objectivists denying all versions of this thesis. Although the differences here will not matter for our purposes, we will generally work with this second way of characterising the debate.

As well as asking how the doctor ought to act, we can also ask what the doctor ought to believe about which drug will cure her patient. Some might think that she ought to believe that drug B is the cure, since this is in fact the situation. Others might think that she ought to believe that drug A is the cure, since it's what her evidence overwhelmingly supports. This disagreement stems from disagreement over whether one's epistemic position bears on what one ought to believe. Roughly, perspectivists about the epistemic ought hold that it does; objectivists hold that it does not. ${ }^{2}$

2. In what follows we will have these views in mind when we say 'objectivism' and 'perspectivism', unless otherwise indicated explicitly or by context. While these are views about the epistemic ought, we usually just talk about what you ought or may believe. We don't mean to assume that what you ought to believe simpliciter is what you epistemically ought to believe. Nor 
This dispute can be made precise in parallel ways to the dispute over the practical ought. Again, while we will generally follow the second approach, a fully precise characterisation will not be needed for our purposes. We mostly focus on a particular and paradigmatic objectivist view:

(TRUTH-OвJectivism) For all $p$, you may believe $p$ iff and because $p .3$

This counts as an objectivist view because, according to it, what you may believe is determined by facts that need not be accessible to you.

Truth-Objectivism is formulated in terms of what you may believe rather than what you ought to believe, to avoid making excessive demands on believers (Whiting 2010). But it implies that you ought not believe any falsehoods. As will be relevant later, it is also compatible with the plausible view that you sometimes ought to believe certain truths.

Though our arguments will focus on Truth-Objectivism, they will also have implications for other views which might naturally be thought of as objectivist, in particular the view that you may believe just what you are in a position to know. We will discuss these implications in Section 5.

It will also be useful to have a more precise perspectivist view in mind. We can focus on:

(eVIDENCE-PERSPECTIVISM) For all p, you may believe $\mathrm{p}$ iff and because your evidence sufficiently supports $\mathrm{p}^{4}$

This counts as a perspectivist view because, according to it, what you may believe is determined only by epistemically accessible considerations - those that constitute your evidence. This raises questions about what it is to possess some evidence, what evidential support consists in, and what it is for such support to be sufficient, but the intuitive notions will suffice for present purposes. ${ }^{5}$

do we assume that there is an epistemic sense of 'ought' in natural language. We can think of what you epistemically ought to believe as what you ought to believe relative only to epistemic reasons.

3. The 'may' here and in the statements of the other views has narrow scope. Truth-Objectivism or something close to it has been endorsed by Boghossian (2003), Gibbard (2005), Littlejohn (2012), Schroeder (2015), Shah (2003), Wedgwood (2002; 2013), and Whiting (2010).

4. Evidence-Perspectivism is entailed by the combination of two claims widely held in epistemology: that epistemic justification is a kind of permission, and that it is a matter of having sufficient evidence. Versions of it are explicitly defended by Clifford (1866), Conee \& Feldman (2004), and Gibbons (2013).

5. One might worry about circularity here: isn't sufficient evidence for $\mathrm{p}$ just evidence sufficient for permission to believe $\mathrm{p}$ ? In fact, though, there are several options for giving independent characterisations of sufficient support. For instance, perhaps evidence is sufficient when it gives weightier reasons to believe $\mathrm{p}$ than to not believe $\mathrm{p}$, or when it probabilifies $\mathrm{p}$ above some threshold, or when it couldn't easily be had if $\mathrm{p}$ were false. 
Note that the perspectivist's claim is not that facts about what you ought to believe are themselves always epistemically accessible. Perhaps you can have misleading evidence about what evidence you possess, about what it supports, or about the epistemic ought. ${ }^{6}$

Truth-Objectivists and Evidence-Perspectivists disagree about what one ought to believe in cases like достоR. But you might think that we can make the question go away, by distinguishing between what the doctor ought to believe relative to all the facts, and what she ought to believe relative to her evidence. Then you might doubt that there's any further question about what the doctor ought to believe, tout court.

This worry comes up in the practical case too: it's not obvious that there must be something the doctor ought to do, tout court, as opposed to what she ought to do relative to the facts, and what she ought to do relative to her evidence. 7

That there are multiple senses of 'ought' is uncontroversial. ${ }^{8}$ But it doesn't follow that there is no interesting question about which objectivists and perspectivists are disagreeing. The senses of 'ought' central to ethics and epistemology, and the properties these senses pick out, play important roles in our thought. We can understand the objectivist and perspectivist as disagreeing over whether there is an objectivist sense of 'ought', and corresponding property, that plays these roles.

This approach to the debate is familiar in the practical case. For example, several philosophers have pointed out that reflection on what you ought to do can play a certain role in practical deliberation: you can ask yourself what you ought to do with a view to making up your mind what to do, and the judgment that you ought to $\phi$ can rationally close such deliberation. Perspectivists have argued that only a perspectivist ought can play this role (Broome 2013; Kiesewetter 2011; in press a; Lord 2015).

Arguments of this kind do not require the assumption that 'ought' is univocal, or that there is only one ought of significance to ethics and epistemology. More generally, whether or not there are multiple such oughts in the epistemic or practical domain, there is a substantive question about whether there is an objective ought which plays a significant role in that domain. In this paper, we are interested in whether there is such an ought in the epistemic domain.

The two arguments we will consider have the form just outlined. Each turns

6. Note also that perspectivists need not be 'internalists', in either of two familiar senses: they need not accept that what you may believe supervenes on your non-factive mental states, or that considerations bearing on what you may believe need be accessible by reflection (cf. Conee \& Feldman 2004; Pryor 2001).

7. Wedgwood (2007: Chapter 5.2) and Schroeder (2015) claim that, whether practical or epistemic, 'ought' can have an objective or a perspective-relative sense. See Becker (2016) for further defence and references.

8. See Bronfman and Dowell (in press) for an overview of recent work on 'ought'. 
on an assumption about a role oughts play and uses this assumption to make trouble for objectivism. The first assumption is that it is irrational to do something that you know you ought not do. The second is that you can be guided by what you ought or may do by responding appropriately to reasons. It is open to the objectivist to reject these assumptions. But if the objectivist is to make a substantive claim, she must say something about the role her ought plays which makes it of interest to epistemologists. ${ }^{9}$

It is worth flagging one final assumption. We take it that what you ought to do is determined by the balance of reasons. For instance, when the reasons relevant to what you ought or may do decisively favour doing something, then you ought to do it; when the reasons relevant to what you ought or may do sufficiently favour doing something, you may do it. This assumption is compatible with the versions of objectivism and perspectivism just outlined. We can think of the Truth-Objectivist as holding that inaccessible facts can be reasons bearing on what you ought to do. Thus for the Truth-Objectivist, the fact that not-p always gives you a decisive reason not to believe $\mathrm{p} .{ }^{10}$ The perspectivist, by contrast, holds that when the fact that not- $p$ is inaccessible it is not a reason relevant to what you ought or may believe. In turn, the disagreement might be understood as concerning whether or not the reasons relevant to what you ought to believe can sufficiently support believing falsehoods. We take this to be equivalent to our characterisation of the debate. ${ }^{11}$

\section{The Insufficient Evidence Argument}

In this section we will consider an argument against Truth-Objectivism which parallels a prominent argument against practical objectivism. We will conclude that, while the epistemic objectivist has available replies which her practical counterpart lacks, the argument nevertheless has serious force.

Consider a case of the form

INSUFFICIENT EVIDENCE: Although $\mathrm{p}$ is in fact true, you lack sufficient evidence for $p$ or sufficient evidence for not-p.

9. For arguments that the polysemy of 'ought' can't be used to reconcile epistemic objectivism and perspectivism, see Gibbons (2013: Chapter 3).

10. Schroeder (2015). Henceforth, for brevity, we mostly leave quantifiers implicit.

11. This characterization leaves open whether the reasons relevant to what you ought or may do are all the reasons there are. For instance, some perspectivists hold that reasons need not be accessible but that only accessible reasons bear on what you ought or may do (Lord 2015; contrast Kiesewetter forthcoming a). For a recent overview and discussion of the literature on how reasons determine oughts, see Lord and Maguire 2016. 
In such cases, which are ubiquitous, suspending judgment seems the thing to do.

Here is a simple argument against Truth-Objectivism: in INSUfFICIENT EVIDENCE, the thing to do is suspend judgment on $p$ rather than believe it; so it's not the case that you may believe $p$ iff $p .{ }^{12}$ But this is too quick. The Truth-Objectivist can distinguish between, on the one hand, what you ought and may believe, and, on the other hand, what's rational or blameless to believe. ${ }^{13}$ She can say that believing $p$ in INSUFFICIENT EVIDENCE is irrational but nonetheless permissible.

This distinction is familiar from the practical case, where the objectivist must distinguish between what you ought to do and what's rational or blameless, in order to accommodate cases like ростоR, where some of the relevant considerations are beyond the agent's ken. ${ }^{14}$

However, while this move might successfully block the simple argument, it seems to invite further problems. We can see this by looking at a prominent objection to practical objectivism. Consider:

DOCTOR THREE-DRUGS: A patient has a minor but non-trivial skin complaint. The doctor can prescribe drug A, drug B, or drug C. She knows that one of drug A and drug B will completely cure the patient, while the other will kill her. But she doesn't know, nor does her evidence indicate, which is which. She knows that drug $C$ will relieve the symptoms somewhat but not completely cure the condition. ${ }^{15}$

On an objectivist view, the doctor ought to prescribe whichever of drugs A and $\mathrm{B}$ will in fact cure the patient. But there is clearly some sense in which the thing to do is to give drug C.

The natural objectivist move is the same as for Dоctor: to distinguish between what's permissible and what's rational. Giving drug $C$ is rational, objectivists can say, even though impermissible.

However, the objectivist making this move faces a problem. Suppose objectivism is true and knowable. Then the doctor can know that she ought not prescribe drug C. But, plausibly, knowingly doing what you ought not-knowingly acting impermissibly - is irrational. So giving drug C is irrational. But it isn't. So objectivism is false, or at least unknowable.

Returning now to INSUFFICIENT EVIDENCE, note its structural similarity to DOC-

12. Cf. Feldman $(1988,245)$.

13. Cf. Littlejohn (2012).

14. Alternatively, the Truth-Objectivist can distinguish between what you ought and may believe relative to the facts and what you ought and may believe relative to your epistemic position. Since what is rational to do is plausibly what you subjectively may do, we take this to be equivalent to the option discussed in the text.

15. Cf. Jackson (1991). For structurally similar cases, see Broome (2013: 37-38), Parfit (2011: 159-160), Ross (2012). 
TOR THREE-DRUGS. In both cases there are three options-give drug A, B, or C, and believe, disbelieve, or suspend judgment-and the 'compromise' option seems the way to go. So it might seem that we can run an argument against Truth-Objectivism, using INSUFFICIENT EVIDENCE, just like the argument against practical objectivism that appeals to DOCTOR THREE-DRUGS (cf. Lord 2015; Way \& Whiting 2016). That is, we can argue that the Truth-Objectivist is committed to its being irrational to suspend judgment in INSUFFICIENT EVIDENCE. ${ }^{16}$

However, this is again too quick. For the Truth-Objectivist claims not that you ought to believe $\mathrm{p}$ when it's true, but only that you may do so. This allows that you may also suspend judgment. So Truth-Objectivism does not entail that, in INSUFFICIENT EVIDENCE, suspending judgment is impermissible. Far less does it entail that it is knowably impermissible and therefore irrational.

However, there is a problem for Truth-Objectivism in the vicinity. While something's being true doesn't entail that you ought to believe it, it's nonetheless plausible that you sometimes ought to believe some proposition-for example, when you have decisive evidence for $\mathrm{p}$ and strong reasons to make up your mind about whether p. ${ }^{17}$ Consider:

DOCTOR DECISIVE: A patient has a treatable disease. The doctor is wondering whether drug $\mathrm{A}$ is the cure. In fact it is, and the doctor has obviously decisive, irrefutable evidence for this.

Here, it's plausible that the doctor ought to believe that drug A is the cure. And objectivists can agree. Denying that you ought to believe any old truth does not commit them to denying that you ought to believe important truths when you have decisive evidence for them.

However, consider:

DOCTOR DUbitABLE: Exactly like DOCTOR DECISIVE, except some of the relevant evidence is inaccessible to the doctor, so her evidence regarding whether drug $\mathrm{A}$ is the cure is insufficient.

By the objectivist's lights, the difference between these cases should make no difference to what the doctor ought to or may believe. After all, objectivism is the view that the accessibility of considerations makes no difference to their con-

16. Independently of the objection we focus on here, the objectivist who distinguishes between permissibility and rationality faces a challenge of explaining why it is rational to take the 'compromise' option. This is not straightforward in the practical case (see, e.g., Schroeder 2009; Sylvan 2015; Whiting 2014) and may be more complicated in the epistemic case, since it requires the objectivist to take a view on what kind of considerations provide reasons to suspend judgment.

17. Cf. Kiesewetter (2015). 
tribution to what you ought to do. ${ }^{18}$ So if the Truth-Objectivist accepts that the doctor ought to believe that drug $\mathrm{A}$ is the cure in Doctor Decisive, then she also seems committed to that verdict in DOctor DUbitable.

Now we can run the DOCTOR-THREE-DRUGS-type argument, using DOCTOR DUBITABLE. Given that the doctor lacks sufficient evidence, suspending judgment on whether drug $\mathrm{A}$ is the cure seems the thing to do. The Truth-Objectivist might claim that suspending judgment is rational, even though the doctor ought to believe that drug A is the cure. But it's not clear how to make good on this claim. If the doctor knows Truth-Objectivism, then she can come to know that she ought not suspend judgment. This would, implausibly, make it irrational for her to suspend judgment.

Almost any case where someone ought to believe something could be used in this way to generate a problem for Truth-Objectivism. One way to resist the argument is thus to deny that anyone ever ought to believe anything. ${ }^{19}$ That's a surprising claim, but perhaps not indefensible. We don't necessarily need outright beliefs in order to act. Alternatively, the Truth-Objectivist might maintain that you are permitted to believe all and only truths, but add that possessed evidence for a truth can provide further reasons to believe it, making it the case that you not only may but ought to believe it. However, on this view inaccessible considerations can permit or forbid belief (and hence require non-belief), and yet only accessible ones can require belief (and hence forbid non-belief). It's hard to see how this could be so.

Another option for the Truth-Objectivist is to reject the principle that it's always irrational to knowingly do as you ought not. She could say, as some practical objectivists have said with regard to DOCTOR THREE-DRUGS, that it can be rational to knowingly do as you ought not when this is the only way to avoid risking doing something much worse (Graham 2010; Wedgwood 2013). So, although the doctor in DOctoR DUBITABLE ought not suspend judgment, she is not irrational for doing so, because she thereby avoids risking the much worse outcome of false belief.

One worry about making this move in the epistemic case is that, once it's conceded that suspension of judgment is sometimes impermissible, it's not clear why false belief should always be much worse. So the move won't obviously generalise to all problem cases. There are also worries that apply to the move in

18. The fact that a consideration is accessible could make a difference by being a reason, but that's a different claim.

19. Might she instead deny that anyone ever ought epistemically to believe anything, but accept that sometimes people ought simpliciter to believe things (cf. Nelson 2010; Whiting 2013)? The problem is that it's rational and blameless simpliciter for the doctor to suspend judgment in DocTOR DUBITABLE. So the case, together with DOCTOR DECISIVE, provides an argument against a truthobjectivist view regarding what you ought simpliciter to believe. 
both the epistemic and practical cases. First, it seems to mischaracterise how we reason under uncertainty. It seems natural to think: 'Suspending judgment is the only way to avoid a high risk of getting it wrong, so I ought to suspend judgment'. It does not seem natural to think: 'Suspending judgment is the only way to avoid a high risk of getting it wrong, so, while I ought not suspend judgment, I will do so anyway'. Second, the objectivist making this move is giving up on a natural way of defending the significance of their view. Objectivism is not just the view that there is an objective ought, but that it is of central concern to ethicists or epistemologists. The idea that it's irrational to do what you know you ought (in this sense) not do is a natural way to indicate the significance of this ought. Objectivists taking this line thus owe us an alternative way of explaining the significance and role of what you ought, in their sense, to do.

In sum, while the objection is not as straightforward to make as it might first appear, it seems that cases of insufficient evidence do cause serious problems for Truth-Objectivism, in a way broadly parallel to a familiar argument in the practical case. The Truth-Objectivist admittedly has available some possible responses which her practical counterpart lacks - in particular, she can deny that anyone ever ought to believe anything - but these responses come with high costs.

\section{The Guidance Argument}

In this section we present a different argument against Truth-Objectivism. The rough idea is this. If the fact that $p$ determines that you may believe $p$, then the evidence bearing on whether $\mathrm{p}$ doesn't do any work in determining what you may believe. What's more, this evidence need not obtain because of the fact that $p$. In that case, being guided by the evidence won't amount to believing as you may because that's how you may believe. But evidence gives reasons, and reasons can get you to do as you may because you may do it. So it can't be that the fact that $\mathrm{p}$ always determines what you may believe. ${ }^{20}$

In order to give a more precise statement of the argument, we introduce two pieces of terminology. First, when someone does something because they may do it, we will say that they do it permissibly. Thus, believing permissibly is not just believing what it is permissible to believe, but believing because it is permissible

20. The idea that externalist views of what one may, ought, or is justified in believing are in tension with the role that these notions play in guiding our beliefs is familiar (cf. Pollock \& Cruz 1999: 13off; Neta 2016; see Goldman 1999 for an important discussion and further references). Our argument here targets only one form of externalism - it is not a general argument against externalism as traditionally understood (cf. Footnote 6). It makes no appeal to the idea that the grounds for epistemic permissions and requirements must be accessible by reflection alone, or that such permissions and requirements must themselves be accessible. 
to believe. ${ }^{21}$ Second, we will talk of explanatorily independent evidence. To understand this, note that some evidence obtains because of the fact it is evidence for. Inference to the best explanation provides obvious examples of this. Not all evidence is like this, however. Explanatorily independent evidence is evidence for a proposition $p$ that neither includes $p$ nor obtains because of the fact that $p$. It includes:

- Simple inductive evidence for propositions about the future, e.g., the evidence that the sun will rise tomorrow given by past sunrises.

- Evidence for the occurrence of effects, given by their causes, e.g., the evidence that the wood burned, given by the fact that it was set alight.

- Evidence for the occurrence of effects, given by co-caused effects, e.g., the evidence that the wood burned, given by the fact that the matches are spent.

- Evidence for instantiations given by their generalisations, where the generalisation isn't true because of its instances, e.g., the evidence that Rover is a mammal, given by the fact that Rover is a dog and dogs are mammals.

These are all cases of explanatorily independent evidence. Tomorrow's sunrise doesn't explain past sunrises;, ${ }^{22}$ the wood's having burned doesn't explain its having been set alight or the matches' being spent; Rover's being a mammal does not explain his being a dog or dogs' being mammals.

Now we can state the Guidance Argument:

1. Explanatorily independent evidence can give undefeated reasons for belief. (Assumption)

2. When you reason well from (respond appropriately to) undefeated reasons, you thereby come to do what you do permissibly. (Assumption)

3. So, there can be cases in which you reason from explanatorily independent evidence to belief and thereby come to believe permissibly. (From 1, 2)

4. According to Truth-Objectivism, whether you may believe $\mathrm{p}$ is fixed by whether p. (Assumption)

21. The distinction here is akin to that between doxastic and propositional justification. For this use of 'permissibly' see Hanser (2005). One might worry that we are here committing to causation by the normative. We do not see this as a problem if so (Arpaly \& Schroeder 2014, Wedgwood 2007). But what matters is just that normative facts can be explanatory. While there are difficult issues about what this involves, it remains very plausible that it is true. For example, to anticipate, when you respond appropriately to the reasons that permit you to $\phi$, your $\phi$-ing is explained by your having reasons that permit you to $\phi$.

22. Even if the justification for induction is ultimately abductive (cf. Harman 1965; Lipton 1991), the facts that constitute your evidence that the sun will rise tomorrow do not obtain because it will do so. 
5. When you reason from explanatorily independent evidence for $p$ to $p$, you thereby come to believe $\mathrm{p}$ because of the evidence, and not because $\mathrm{p}$. (Assumption)

6. So, if Truth-Objectivism is true, then, whenever you reason from explanatorily independent evidence for $p$ to $p$, you do not come to believe $p$ permissibly. (From 4, 5)

7. So, Truth-Objectivism is false. (From 3,6 )

Now we will go through the steps of the argument.

Premise 1 seems hard to deny on pain of sceptical consequences. Above, we gave examples of explanatorily independent evidence. We often base beliefs on evidence of these sorts, and these beliefs can be in perfectly good standing - they can be justified and constitute knowledge. They need not be at all faultily based. So such evidence must sometimes give reasons for belief, and these reasons must sometimes be undefeated.

An objectivist will say that, when $p$ is false, any reasons given by evidence for $p$ are defeated by this fact. But that's compatible with 1 , which says that explanatorily independent evidence can give undefeated reasons for belief, not that it always does so. When $\mathrm{p}$ is true and there is no evidence against it (or undercutter of the evidence for it), there don't seem to be any candidates for being (undefeated) defeaters for the reasons to believe $p$, even by the objectivist's lights. ${ }^{23}$

Premise 2 gets support from examples: if the fact that you promised to $\phi$ is an undefeated reason to intend to $\phi$, and you form this intention by reasoning well from (responding appropriately to) this fact, then it seems that you intend permissibly. But can we say something more principled in its defence? We think so. Firstly, the truth of 2 seems required for a plausible view of guidance by normative permissions and requirements. On one view, such guidance requires you to explicitly entertain the requirements using the concepts may and ought. But this seems too demanding. On a less demanding account, you can be guided by permissions and requirements by responding appropriately to reasons - to the (typically non-normative) facts that determine the permissions or requirements. ${ }^{24}$ There are interesting questions about what exactly responding appropriately in this sense involves but that it occurs should not be controversial.

23. E.g., Schroeder (2015) holds that p's being false is an objective defeater for any evidence for $\mathrm{p}$, but allows that evidence that falls short of $\mathrm{p}$ can give sufficient objective reason to believe $\mathrm{p}$, provided that $\mathrm{p}$ is true (cf. also Littlejohn 2012).

24. Cf. Arpaly \& Schroeder (2014: Chapter 3), Lord (in press a), Markovits (2010a), Way (in press) on morally worthy action. One might question the idea of being guided by a permission. After all, even if $\phi$-ing is permitted, it may not be worth doing. However, this does not show that we cannot be partially guided by a permission. This is all that's needed for our purposes. 
Whatever it involves, the notion of 'reasoning well' deployed in the Guidance Argument should be understood as entailing it. In sum, then, reasoning well from undefeated reasons, in an appropriate sense of 'reasoning well', must be sufficient for responding permissibly, since nothing further could plausibly be necessary. 25

The second principled line of defence of 2 appeals to the roles of reasons. Reasons determine what you ought and may do (or so we are assuming). But reasons can also guide reasoning - they can be responded to. ${ }^{26}$ It is surely not a coincidence that reasons have these two features. They are connected: you are guided by what you ought or may do when you respond appropriately to the reasons that determine this. In particular, when you respond to undefeated reasons, you are guided by what you may do, and thus respond permissibly.

Objectivists need not and should not deny that reasons can guide reasoning. They should just refrain from understanding this use of 'can' as meaning 'can given the agent's actual epistemic situation'. There's a sense of 'can' in which it's true to say that a reason can guide your reasoning, even if you are not aware of it. ${ }^{27}$

From 1 and 2, it follows that there can be cases in which you reason from explanatorily independent evidence and thereby believe permissibly (Lemma 3). ${ }^{28}$ The remainder of the argument shows that this consequence is incompatible with objectivism.

Premise 4 follows from the statement of Truth-Objectivism.

Premise 5 states that when you come to believe $p$ by reasoning from explanatorily independent evidence for $p$, you thereby believe $p$ because of the evidence, and not because of $\mathrm{p}$. This assumption seems undeniable. Since evidence can obtain because of the fact it is evidence for, there might be cases where you count as believing $\mathrm{p}$ both because of the evidence and because $\mathrm{p}$. But when evidence is explanatorily independent, your believing on its basis will not amount to believing because of the fact. For example, my belief that the sun will rise tomorrow, based on past sunsets, is not explained by the fact that the sun will rise tomor-

25. We allow that having explicitly normative thoughts can also be a way of being guided by normative requirements and permissions.

26. While both of these claims about reasons are widely accepted (for the first see, e.g., Broome 2013; Parfit 2011; Schroeder 2007; for the second, Gibbons 2013; Kelly 2002; Shah 2006; Williams 1981; for both, Dancy 2000; Raz 2011), some demur. 'Surprise party' reasons might be thought a counterexample to the second claim (Markovits 2010b; Schroeder 2007), but, like others, we don't find this verdict convincing (Kiesewetter 2016; Setiya 2009). Wedgwood (2015) has recently argued that nothing plays both of the roles we assume reasons play. Unfortunately we lack the space to address his arguments here.

27. See Way \& Whiting (in press).

28. We also need the assumption that it is possible to reason well from explanatorily independent evidence. We take this to be uncontroversial. 
row. To claim otherwise would be to posit explanatory relations that simply do not obtain in these cases. ${ }^{29}$

It might be claimed that, when you truly believe or know p, you are thereby in touch with the fact that $p$ in such a way as to be able to respond to it, even if the evidence you have for $p$ is explanatorily independent. ${ }^{30}$ But our concern here is with what you respond to in coming to believe $p$. What's implausible is that you are in touch with the fact that $\mathrm{p}$ even before you've come to believe it, when your evidence is explanatorily independent.

Lemma 6 says that if Truth-Objectivism is true, then reasoning from explanatorily independent evidence for $p$ to $p$ is not a way to come to believe $p$ permissibly. This seems to follow straightforwardly from 4 and 5 . Doing something because of the fact that makes it the case that you may do it can count as doing it permissibly. But doing it because of explanatorily independent evidence for that fact cannot. In such a case the explanatory relations are not set up in the right way for you to count as doing the thing because you may.

The conclusion, 7 , follows from 3 and 6 .

\section{Objections to the Guidance Argument}

We now consider some objections to the Guidance Argument.

One natural place to attack the argument is premise 2. Consider a case where $p$ is true and you have strong explanatorily independent evidence for $p$. As we have argued, the objectivist should grant that this evidence can give you undefeated reason to believe p. However, they will hold that in these cases there is a much weightier reason to believe $p$, namely the fact that $p$. That's because the weight of a reason reflects or is a measure of what opposing reasons it can outweigh. According to Truth-Objectivism, the fact that $\mathrm{p}$ is always sufficient to determine that you may believe $\mathrm{p}$. It thus cannot be outweighed by contrary evidence. Explanatorily independent evidence, by contrast, can be so outweighed. The fact that $\mathrm{p}$ is thus a weightier reason than the explanatorily independent evidence.

The Truth-Objectivist may now claim that 2 fails in cases where the undefeated reason that you respond to is much less weighty than another reason that favours the same response. For example, suppose Jack promises to meet Jill for lunch, and that he would also enjoy doing so. We can imagine that both the en-

29. Of course, in different contexts, different factors can felicitously be cited to explain the same thing. But that doesn't mean that anything goes. Note also that, if the 'because' in 5 is understood causally, as seems natural, denial of 5 would involve a commitment to backwards causation in some cases.

30. Cf. Hyman (2015: Chapter 7). 
joyment and the promise are undefeated reasons for Jack to meet Jill, but that the promise is a much weightier reason..$^{31}$ If Jack meets Jill for lunch only on the basis that he would enjoy it, ignoring the promise, he does as he may, but arguably not because he may. To act permissibly, he would have to respond to the much weightier reason given by his promise. So, 2 is false.

The arguments for 2 can be accommodated by pointing out that something close to it might still be true:

$2^{*}$. When you reason well from undefeated reasons, and do not ignore much weightier reasons, you thereby come to do what you do permissibly.

Can the Guidance Argument be revamped, using $2^{*}$ instead of 2? For this, 1 would need to be replaced with something like:

$I^{*}$. Explanatorily independent evidence can give undefeated reasons for belief, and there need be no much weightier reason that you ignore in reasoning from it.

But the point of the present objection is that, when some explanatorily independent evidence gives undefeated reason to believe $\mathrm{p}$, there is always another, weightier consideration - namely the fact that $\mathrm{p}$. So the Truth-Objectivist pursuing this objection will reject $1^{*}$.

While this objection has some force, the view that it leaves the TruthObjectivist with is unattractive. It entails that explanatorily independent evidence is guaranteed to be irrelevant to what you may believe, since it will either be defeated (if $\mathrm{p}$ is false) or 'screened off' by a much weightier reason (if $\mathrm{p}$ is true). Moreover, such evidence does not seem suitable for reasoning with, on this view, since by reasoning with it you are sure to be ignoring a much weightier consideration and failing to be guided by what you may or ought to do. ${ }^{22}$

31. It might be claimed that the enjoyment is defeated by the promise, even though these reasons are not opposed. Similarly, we might deny 1 and claim that non-misleading explanatorily independent evidence is defeated by the fact it is evidence for. However, the idea of evidence being defeated by the fact that it is evidence for seems dubious, and anyway this version of the objection would face the same problems as the one we consider in the text.

32. This assumes that something cannot be suitable for reasoning with if it ensures that you are not being guided by what you may or ought to do. The objectivist might deny this assumption. But doing so leads to a dilemma. Either the point of reasoning is to ensure that you do what you may or ought to do, or it isn't. If it is, then considerations guaranteed to be irrelevant to this point seem patently unsuitable for reasoning. If it isn't, then, firstly, this undermines one of the main motivations for objectivism - roughly, the fact that, in reasoning, we attend to the facts rather than to our epistemic perspective. Secondly, it again raises the question why we should care about the 
Since it neither determines what you may do nor is suitable to guide reasoning, it's hard to see how such evidence could count as reason-giving at all. In that case, the Truth-Objectivist seems committed to denying not only $I^{*}$ but also $I$ (and even the weaker claim that explanatorily independent evidence can give some reason for belief). As we argued above, this would have implausible sceptical consequences. So, if we accept the replacement of 2 with $2^{*}$ for the reasons given above, we can still rescue the Guidance argument by insisting that $1^{*}$ must be accepted, on pain of scepticism.

Note that, in the practical case, we don't seem to find reasons which are guaranteed to be irrelevant to what you may or ought to do. For example, the fact that you would enjoy $\phi$-ing might sometimes be less weighty than some other reason, but it is at least the sort of thing that can make it the case that you may or ought to $\phi .33$

Another way to attack the Guidance Argument is to deny that 6 follows from 4 and 5 . There are a couple of ways this might be done.

To begin with, it might be said that the inference from 4 and 5 to 6 ignores the variety of ways in which you can come to do something permissibly. We argued that one way of $\phi$-ing permissibly is to reason well from considerations that permit you to $\phi$. But it might be suggested that you can also come to $\phi$ permissibly by reasoning well from considerations that provide sufficient evidence that you may $\phi$, or from considerations that couldn't easily obtain if you may not $\phi$.

However, it's not generally true that doing something because of evidence for $p$, or because of considerations that couldn't easily obtain if not-p, is a way of doing that thing because $\mathrm{p}$. In particular, when $\mathrm{p}$ is not among, and does not explain, the considerations for which you do something - that is, when those considerations are explanatorily independent of $\mathrm{p}-$ it is hard to see how you count as doing that thing because of $p$. For example, if I buy new matches because the old ones are spent, I do not thereby count as buying matches because the wood burned.

The difficulty here suggests a second way to deny that 6 follows from 4 and 5. Though Truth-Objectivism says that whether you may believe $\mathrm{p}$ is fixed by whether $\mathrm{p}$, it does not say that it is fixed only by whether $\mathrm{p}$. Thus the TruthObjectivist might insist that explanatorily independent evidence does play a role

objectivist ought. And, thirdly, it would fit better with a perspectivist view, as we explain below (Section 5.3).

33. Even in the practical case there are reasons that don't play all the typical roles of reasons. For example, on some views the fact that you ought to $\phi$ is a reason to $\phi$, though it does not help make it the case that you ought to $\phi$. And the fact that $X$ is good is a reason to value $X$, but doesn't add weight to the other reasons to value $X$, since it consists in the obtaining of those reasons. Still, these seem like limiting cases that we can explain in a principled way. Evidence for p does not look like this. Furthermore, that these considerations are reasons is plausible only in so far as they do seem appropriate for guiding reasoning. 
in determining what you may believe. In particular, in a case in which $p$ is true, the fact that you may believe $p$ is overdetermined: you may believe $p$ both because $\mathrm{p}$ and because of the explanatorily independent evidence for $\mathrm{p}$. And in that case, reasoning well from such evidence can be a way to come to believe p permissibly, even given the assumption just challenged, for it will amount to reasoning from considerations which determine that you may believe $p$.

This objection is also problematic. First, the position it leaves the TruthObjectivist with again looks awkward. While it allows a sense in which explanatorily independent evidence for $\mathrm{p}$ can provide undefeated reasons which bear on what one may believe, these reasons are guaranteed to be either redundant (if $\mathrm{p}$ is true) in the sense that they make no difference to what one may believe, or defeated (if $\mathrm{p}$ is false). This seems an odd consequence, without a clear parallel in the practical case. ${ }^{34}$ Furthermore, it remains surprising that you could count as responding permissibly-i.e., because your response is permissible-by responding to considerations of a kind which are guaranteed to make no difference to whether your response is permissible.

Second, and as noted above, the Truth-Objectivist has to grant that, even when undefeated, explanatorily independent evidence for $\mathrm{p}$ provides a far weaker reason to believe $\mathrm{p}$ than the fact that $\mathrm{p}$. But as we also saw above, it seems that when you reason well from undefeated but relatively weak reasons to $\phi$ you do not thereby come to $\phi$ permissibly - when Jack meets Jill because he would enjoy doing so, and not because he promised, he arguably doesn't act permissibly. Thus it's not clear that the Truth-Objectivist's line here does allow that believing on the basis of explanatorily independent evidence is a way to believe permissibly.

In response, it might be suggested that we have misdiagnosed what's problematic about Jack's case. Jack doesn't act permissibly, it might be said, not because he fails to respond to a stronger reason, but because he fails to respond to a decisive reason. If Jack's reasons were both merely sufficient-for instance, because he also had a strong reason to stay home - then there wouldn't be anything problematic about responding just to the enjoyment, and not the promise. So this case doesn't show that there's anything problematic as such about ignoring stronger reasons.

This response may be right as far as it goes: perhaps when you have only

34. It might be replied that some views of practical reasons do allow for parallel cases. For instance, Star (2015: esp. Chapter 1) defends a view on which classical ethical theories such as utilitarianism and Kantian deontology should be understood as specifying fundamental reasons. Derivative reasons are then provided by evidence of fundamental reasons. It might seem that on this view, derivative reasons are guaranteed to be redundant (if the fundamental reason also obtains) or defeated (if it doesn't). However, even if the view does have this consequence, it is not clear that it provides a parallel case, since it's not clear that derivative reasons of this sort determine what you ought to do-on Star's view, this is the role of fundamental reasons (though see Kearns \& Star 2008: 48-49). In any case, as we note in Section 5.2 , this view of reasons remains highly contentious. 
sufficient reasons, acting for some sufficient reason can be enough to act permissibly. However, even if it can be enough, it's far less clear that it always is; in particular, as noted above, it's not clear that it is when the reason acted on is guaranteed to make no difference to what you may do. In any case, a restricted version of the lesson we drew from Jack's case still seems to hold: in cases where you have two decisive reasons to do something, but one of these reasons is much weaker than the other, you do not $\phi$ permissibly if you reason only from the weaker reason. A refinement of Jack's case illustrates this. Suppose that Jack has no pressing reasons not to meet Jill, or to do anything else, so that both the promise and the enjoyment are decisive reasons to meet her. ${ }^{35}$ Still, it seems that Jack doesn't act permissibly if he responds to the enjoyment and ignores the promise. We can bring this out by noting that acting permissibly plausibly makes you creditworthy, or at least makes you immune from criticism. ${ }^{36}$ But Jack does still seem criticisable if he ignores the promise.

This restricted claim is enough to cause problems for the Truth-Objectivist's response here. That is because it is plausible that explanatorily independent evidence can give decisive reason to believe $\mathrm{p}$. This will be plausible, for instance, in cases in which you have strong reason to make up your mind about $p$, as in DOCтоR DECISIVE (Section 2). In those cases, it will also be plausible that the fact that $\mathrm{p}$ gives you a decisive reason to believe $\mathrm{p}$. The Truth-Objectivist response we are considering says that in such cases you can come to permissibly believe $\mathrm{p}$ by reasoning well from the evidence for $\mathrm{p}$, since that evidence determines that you may-indeed, ought to-believe p. But Jack's case suggests that reasoning well from even a decisive reason need not ensure that you $\phi$ permissibly, if you are also ignoring a much stronger reason.

We conclude that these objections do not allow the Truth-Objectivist to resist the Guidance Argument in a plausible way.

\section{Implications}

In this section we discuss some implications of the discussion so far.

\subsection{Knowledge}

We've been talking about a particular version of objectivism, but others are possible. Consider:

35. We make the standard assumption (cf. Lord \& Maguire 2016) that a reason to $\phi$ is decisive if it outweighs all conflicting reasons.

36. See works cited in Footnote 24.

Ergo • vol. 4, no. 5 • 2017 
(KNOWLEDGE-PERMISSION) For all p, you may believe $\mathrm{p}$ iff and because you're in a position to know $\mathrm{p}$.

Is this a version of objectivism? Here it matters how we carve the terrain. If objectivism is the denial that what you ought or may believe supervenes on your epistemic position, then this view counts as perspectivist. If objectivism is the denial that the considerations which determine what you ought or may believe must be epistemically accessible to you, then this view counts as objectivist, if facts about (or that determine) what you're in a position to know are not always accessible to you.

However we resolve this terminological issue, Knowledge-Permission avoids the objections in this paper. In INSUFFICIENT EVIDENCE, belief will be impermissible, regardless of what reasons you have to make up your mind. So there will be no problem accommodating the fact that suspending judgment is the thing to do. And explanatorily independent evidence can help to determine whether you are in a position to know. So, given Knowledge-Permission, believing on the basis of such evidence can arguably count as believing permissibly.

Knowledge-Permission may also seem broadly in the spirit of TruthObjectivism insofar as, for example, it holds that false belief is impermissible. Some might thus take the lesson of this paper to be that Truth-Objectivists should turn to Knowledge-Permission.

However, we think this is too quick. For we can ask, what view of the practical ought should Knowledge-Permission combine with? The answer isn't obvious. In so far as it is an objectivist view, the natural suggestion might be that it should go with objectivism about the practical ought. But this leads to problems. Consider достоR. Given practical objectivism, the doctor ought to give drug Bthe drug that will in fact cure the patient. But given Knowledge-Permission, the doctor may not believe that drug B will cure the patient, and may believe that reliable sources indicate the drug B will kill the patient and that another available drug will cure her. Given the agglomeration principle that if you may $\phi$ and you ought to $\psi$ then you may $\phi$ and $\psi$, the doctor may give drug $B$ while holding this latter belief. But it seems reckless to give drug B while holding this belief. While there may be cases where such conduct is permitted-e.g., moral dilemmas, or cases of misleading higher-order evidence- DостоR is not like them. It's just a case of ordinary misleading evidence.

In view of this, perhaps the Knowledge-Permissivist should instead go perspectivist on the practical ought. But this would still yield odd results. For example, the doctor would be required to give drug A but not permitted to believe that it is the cure. Indeed, given another agglomeration principle-that if you're required to $\phi$ and required to $\psi$, you're required to $\phi$ and $\psi$-she would be required to give drug A while not believing that it is the cure. 
Furthermore, if the motivation for Knowledge-Permission is sympathy with 'knowledge first' epistemology, then there are more plausible options that seem equally well motivated. One could, for example, be an Evidence-Perspectivist, and hold that your evidence is just what you know. This would make knowledge central to determining what you may believe, but allow that you may sometimes believe things you are not in a position to know. 37

\subsection{Objectivism about the Practical Ought}

As we have seen, the Insufficient Evidence Argument has a practical analogue. Does the Guidance Argument?

Consider the view that you ought to act just when so acting will be best, given all the facts. This view will be susceptible to a version of the Guidance Argument if there are cases in which we have undefeated 'value-independent' reasons to act-reasons to act which are not facts about value or facts in virtue of which so acting is valuable. Some philosophers hold that there are such cases. Kearns \& Star (2009), Lord (in press b), and Markovits (2010) hold that evidence that you ought to act in some way is a reason to act that way, whether or not that evidence is explained by the value of so acting.

If these philosophers are right, we can run a version of the Guidance Argument against this version of objectivism - we just need to replace reference to 'explanatorily independent evidence' and to belief with reference to 'valueindependent reasons' and to action, and to plug in the above version of objectivism. However, we take this version of the argument to be less forceful than its epistemic analogue. That is because the assumption that there are valueindependent reasons to act is much more contentious than the assumption that there are explanatorily independent reasons to believe (for example, the thesis that evidence that you ought to $\phi$ is a reason to $\phi$ is disputed by Broome, 2008, Brunero, 2009, and McKeever \& Ridge, 2012). Thus the proponent of this version of objectivism can escape the argument by denying this assumption.

However, even aside from this practical analogue of the Guidance Argument, epistemic perspectivism still provides some support for practical perspectivism, for several reasons.

First, it would be prima facie surprising for the epistemic ought to be perspectivist and the practical ought to be objectivist; it seems natural to expect them to behave the same. ${ }^{38}$

Second, like Knowledge-Permission, a 'hybrid' view gives strange results in cases like ростов. On the hybrid view, the doctor may believe that drug B will

37. Cf. Gibbons (2013).

38. Skorupski (2010) endorses, but does not argue for, a 'hybrid' view. See Way \& Whiting (2016) for discussion. 
kill the patient, but ought to give drug B. Given the relevant agglomeration principle, it follows that the doctor may give drug B while believing that it will kill her patient.

Third, there is reason to think that this sort of outcome can never occur. The doctor, we are supposing, is permitted to believe that drug A is the cure. Suppose she thinks 'Drug A is the cure, so I ought to give drug A, so I shall give drug $\mathrm{A}^{\prime}$. This looks like good reasoning. But it is plausible that good reasoning transmits permission. So she may intend to give drug A. But surely if she may intend to give it, she may give it. So it's not the case that she ought not give it, as the objectivist claims. ${ }^{39}$

\subsection{Doxastic Deliberation}

Finally, we want to consider one argument for objectivism. We focus on this argument not because we take it to be the only, or the best, argument for objectivism - the case for objectivism is not the topic of this paper-but rather because it brings out some important distinctions which bear on the preceding discussion.

It seems platitudinous that in doxastic deliberation you try to work out what's true. It also seems plausible that there are important connections between doxastic deliberation and what you ought to, and may, believe. For instance, Shah (2003) suggests that in doxastic deliberation we aim to believe what we ought to believe. If so, wouldn't this suggest that, at least in doxastic deliberation, we assume that we ought to believe only what's true?

We can begin to accommodate these considerations by distinguishing between what you ought and may believe, and what is correct to believe. True belief is correct belief and false belief is incorrect belief. Correctness for belief is thus objective. And in doxastic deliberation you're interested in believing correctly.

This move raises two questions. First, if doxastic deliberation aims at truth and thereby at correct belief, what is the connection between doxastic deliberation and what you ought to or may believe? Second, isn't 'correct' just another term for 'ought' or 'may'?

Here's a rough answer to the first question. Both correctness and ought/may are related to deliberation, but in different ways. What you're aiming to do in deliberation is to get things right. Whether you succeed in this aim is not entirely determined by whether you deliberate well or badly: you might deliberate impeccably, and still end up with an incorrect belief, for example if your evidence

39. For more on the argument in this paragraph see Way \& Whiting (2016). See Kiesewetter (2016) for another argument against objectivism about the practical ought based on perspectivism about the epistemic ought. 
is misleading. However, if you deliberate well from your reasons, you will end up believing as you may. Crucially, the gap between what's correct to believe and what you may believe cannot show up from your point of view. What you may believe is determined by your reasons, which are given by your evidence. But your evidence is your guide to what's true.

The deeper explanation of this, we suggest, has to do with what it is to be a reason. On our view, the nature of reasons is ultimately explained in terms of correctness. This explains why only evidence gives reasons for belief: only evidence is appropriately connected to the standard of correctness for belief. Since what you ought and may believe is determined by your reasons, it also explains why deliberation, while ultimately aiming at correctness, can get you to believe as you ought or may when you do it well..$^{\circ}$

Although what you may believe and what's correct to believe are indistinguishable from your point of view, they are distinct. What you ought and may believe is determined by reasons. What's correct or incorrect to believe is not: it's a matter of what's true and false. So, the answer to the second question above is no.

An opponent might press: if what you call correctness and incorrectness for belief are normative, doesn't this mean that they are a matter of what you ought, may and ought not believe? But this question rests on an inappropriately limited conception of normative properties. We have to recognise that correctness and incorrectness are not to be understood in terms of ought and may; indeed, on our view, the opposite is true. Correctness and incorrectness are not determined by reasons that weigh against each other but by a certain sort of match between an attitude and its object. If someone says that correctness is what they meant all along by 'objective ought', then fine-but this property does not have the features that are standardly attributed to ought properties: being determined by how reasons weigh up, and the connections to rationality and guidance that we have appealed to in this paper..$^{11}$

\section{Conclusion}

We have defended perspectivism about the epistemic ought by presenting two arguments against the most natural objectivist view. We have argued that both have significant force. While we have not argued that either is decisive, we have tried to show that the most natural responses to these arguments come with significant costs. Finally, we showed that our arguments also raise problems for the

40. For further discussion see McHugh \& Way (2016).

41. For more on the distinctiveness of correctness, or 'fittingness', see Chappell (2012), McHugh \& Way (2016), Svavarsdóttir (2014). 
view that you may believe just what you are in a position to know, that they put pressure on practical objectivism, and that they support a distinction between correctness and what you ought or may do.

\section{Acknowledgments}

For valuable feedback, thanks to Alex Gregory, Benjamin Kiesewetter, Daniel Whiting, two referees for Ergo, and audiences at the University of Birmingham, the University of Southampton, and Queen's University Belfast. This work was supported by the Arts and Humanities Research Council [grant number AH/ Koo8188/1].

\section{References}

Arpaly, Nomy and Tim Schroeder (2014). In Praise of Desire. Oxford University Press. Becker, Sebastian (2016). Perspectives on What to Believe: The Information-Sensitivity of the Doxastic 'Should' and its Implications for Normative Epistemology (Doctoral dissertation). University of St. Andrews. Retrieved from https://research-repository.st-andrews. ac.uk/handle/10023/9890

Berker, Selim (2013). Epistemic Teleology and the Separateness of Propositions. Philosophical Review, 122(3), 337-393. https://doi.org/10.1215/o0318108-2087645

Bronfman, Aaron and Janice Dowell (in press). The Language of Reasons and Ought. In D. Star (Ed.), Oxford Handbook of Reasons. Oxford University Press.

Broome, John (2008). Reply to Southwood, Kearns \& Star, and Cullity. Ethics, 119(1), 96108. https://doi.org/10.1086/592584

Broome, John (2013). Rationality through Reasoning. Wiley-Blackwell. https://doi. org/10.1002/9781118609088

Brunero, John (2009). Reasons and Evidence One Ought. Ethics, 119(3), 538-545. https:// doi.org/10.1086/597594

Chappell, Richard (2012). Fittingness: The Sole Normative Primitive. Philosophical Quarterly. 62(249), 684-704. https://doi.org/10.1111/j.1467-9213.2012.00075.x

Clifford, W. K. (1866). The Ethics of Belief. In Lectures and Essays (Vol. 2, 177-211). Cambridge University Press.

Conee, Earl and Richard Feldman (2004). Evidentialism. Oxford University Press. https:// doi.org/10.1093/0199253722.001.0001

Dancy, Jonathan (2000). Practical Reality. Oxford University Press.

Feldman, Richard (1988). Epistemic Obligations. Philosophical Perspectives, 2, 235-256. https://doi.org/10.2307/2214076

Gibbons, John (2013). The Norm of Belief. Oxford University Press. https://doi.org/10.1093/ acprof:0so/9780199673391.001.0001

Graham, Peter (2010). In Defence of Objectivism about Moral Obligation. Ethics, 121(1), 88-115. https://doi.org/10.1086/656328 
Goldman, Alvin (1999). Internalism Exposed. Journal of Philosophy, 96(6), 271-293. https:// doi.org/10.2307/2564679

Hanser, Matthew (2005). Permissibility and Practical Inference. Ethics, 115(3), 443-470. https://doi.org/10.1086/428457

Harman, Gilbert (1965). The Inference to the Best Explanation. Philosophical Review, 74(1), 88-95. https://doi.org/10.2307/2183532

Hyman, John (2015). Action, Knowledge, and Will. Oxford University Press. https://doi. org/10.1093/acprof:0so/9780198735779.001.0001

Jackson, Frank (1991). Decision-Theoretic Consequentialism and the Nearest and Dearest Objection. Ethics, 101(3), 461-482. https://doi.org/10.1086/293312

Kearns, Stephen and Daniel Star (2008). Reasons: Explanations or Evidence? Ethics, 119(1), 31-56. https://doi.org/10.1086/592587

Kearns, Stephen and Daniel Star (2009). Reasons as Evidence. In Russ Shafer-Landau (Ed.), Oxford Studies in Metaethics (Vol. 4, 215-242). Oxford University Press.

Kelly, Thomas (2002). The Rationality of Belief and Some Other Propositional Attitudes. Philosophical Studies, 110(2), 163-196. https://doi.org/10.1023/A:1020212716425

Kiesewetter, Benjamin (2011). 'Ought' and the Perspective of the Agent. Journal of Ethics and Social Philosophy, 5(3), 1-24.

Kiesewetter, Benjamin (2015). Can the Lottery Paradox Be Solved by Identifying Epistemic Justification with Epistemic Permissibility? Manuscript submitted for publication.

Kiesewetter, Benjamin (2016). You Ought to $\Phi$ Only If You May Believe That You Ought to $\Phi$. The Philosophical Quarterly, 66(265), 760-782. https://doi.org/10.1093/pq/pqw012

Keisewetter, Benjamin (in press a). How Reasons Are Sensitive to Available Evidence. In Conor McHugh, Jonathan Way, and Daniel Whiting (Eds.), Normativity: Epistemic and Practical. Oxford University Press.

Littlejohn, Clayton (2012). Justification and the Truth-Connection. Cambridge University Press. https://doi.org/10.1017/cbo9781139060097

Lipton, Peter (2004). Inference to the Best Explanation (2nd ed.). Routledge.

Lord, Errol (2015). Acting for the Right Reasons, Abilities, and Obligation. In Russ ShaferLandau (Ed.), Oxford Studies in Metaethics (Vol. 10, 26-52). Oxford University Press. https://doi.org/10.1093/acprof:0so/9780198738695.003.0002

Lord, Errol (in press a). On The Intellectual Conditions for Responsibility: Acting for the Right Reasons, Conceptualisation, and Credit. Philosophy and Phenomenological Research.

Lord, Errol (in press b). What You're Rationally Required To Do and What You Ought To Do (Are The Same Thing!). Mind.

Lord, Errol and Barry Maguire (2016). An Opinionated Guide to the Weight of Reasons. In Errol Lord and Barry Maguire (Eds.), Weighing Reasons (3-24). Oxford University Press. https://doi.org/10.1093/acprof:0so/9780199315192.003.0001

Markovits, Julia (2010a). Acting for the Right Reasons. Philosophical Review, 119(2), 201242. https://doi.org/10.1215/00318108-2009-037

Markovits, Julia (2010b). Internal Reasons and the Motivating Intuition. In M. Brady (Ed.), New Waves in Metaethics (141-165). Palgrave-Macmillan.

McHugh, Conor and Jonathan Way (2016). Fittingness First. Ethics, 126(3), 575-606. https://doi.org/10.1086/684712 
McKeever, Sean and Michael Ridge (2012). Elusive Reasons. In Russ Shafer-Landau (Ed.), Oxford Studies in Metaethics (Vol. 7, 110-137). Oxford University Press.

Nelson, Mark (2010). We Have No Positive Epistemic Duties. Mind, 119(473), 83-102. https://doi.org/10.1093/mind/fzp148

Neta, Ram (2016). Access Internalism and the Guidance Deontological Conception of Justification. American Philosophical Quarterly, 53(2), 155-167.

Parfit, Derek (2011). On What Matters (Vol. 1). Oxford University Press.

Pollock, John and Joseph Cruz (1999). Contemporary Theories of Knowledge (2nd ed.). Rowman and Littlefield.

Pryor, James (2001). Highlights of Recent Epistemology. British Journal for the Philosophy of Science, 52(1), 95-124. https://doi.org/10.1093/bjps/52.1.95

Raz, Joseph (2011). From Normativity to Responsibility. Oxford University Press. https:// doi.org/10.1093/acprof:0so/9780199693818.001.0001

Ross, Jacob (2012). Rationality, Normativity, and Commitment. In Russ Shafer-Landau (Ed.), Oxford Studies in Metaethics (Vol. 7, 138-181). Oxford University Press.

Schroeder, Mark (2007). Slaves of the Passions. Oxford University Press. https://doi. org/10.1093/acprof:0so/9780199299508.001.0001

Schroeder, Mark (2015). Knowledge is Belief for Sufficient (Objective and Subjective) Reason. In Tamar Szabo Gendler and John Hawthorne (Eds.), Oxford Studies in Epistemology (226-252). Oxford University Press. https://doi.org/10.1093/acprof:o so/9780198722762.003.00o8

Setiya, Kieran (2009). Reply to Bratman and Smith. Analysis, 69(3), 531-540. https://doi. org/10.1093/analys/anpo83

Shah, Nishi (2003). How Truth Governs Belief. Philosophical Review, 112(4), 447-482. https://doi.org/10.1215/00318108-112-4-447

Shah, Nishi (2006). A New Argument for Evidentialism. The Philosophical Quarterly, 56(225), 481-498. https://doi.org/10.1111/j.1467-9213.2006.454.x

Skorupski, John (2010). The Domain of Reasons. Oxford University Press. https://doi. org/10.1093/acprof:0so/9780199587636.001.0001

Star, Daniel (2015). Knowing Better. Oxford University Press. https://doi.org/10.1093/acpr of:0so/9780199570416.001.0001

Svavarsdóttir, Sigrún (2014). Having Value and Being Worth Valuing. Journal of Philosophy, I11(2), 84-109. https://doi.org/10.5840/jphil201411125

Sylvan, Kurt (2015). What Apparent Reasons Appear to Be. Philosophical Studies, 172(3), 587-606. https://doi.org/10.1007/s11098-014-0320-1

Way, Jonathan (in press). Creditworthiness and Matching Principles. In Mark Timmons (Ed.), Oxford Studies in Normative Ethics (Vol. 7). Oxford University Press.

Way, Jonathan and Daniel Whiting (2016). If You Justifiably Believe That You Ought to $\Phi$, Then You Ought to $\Phi$. Philosophical Studies, 173(7), 1873-1895. https://doi.org/10.1007/ S11098-015-0582-2

Way, Jonathan and Daniel Whiting (in press). Perspectivism and the Argument from Guidance. Ethical Theory and Moral Practice. https://doi.org/10.1007/s10677-016-9775-9

Wedgwood, Ralph (2007). The Nature of Normativity. Oxford University Press. https://doi. org/10.1093/acprof:0so/9780199251315.001.0001

Wedgwood, Ralph (2013). Akrasia and Uncertainty. Organon F, 20(4), 483-505.

Wedgwood, Ralph (2015). The Pitfalls of Reasons. Philosophical Issues, 25(1), 123-143. https://doi.org/10.1111/phis.12054 
Whiting, Daniel (2010). Should I Believe the Truth? Dialectica, 64(2), 213-224. https://doi. org/10.1111/j.1746-8361.2009.01204.x

Whiting, Daniel (2013). Truth: The Aim and Norm of Belief. Teorema, 32(3), 121-136.

Whiting, Daniel (2014). Keep Things in Perspective: Reasons, Rationality, and the A Priori. Journal of Ethics and Social Philosophy, 8(1), 1-22.

Williams, Bernard (1981). Internal and External Reasons. In Moral Luck (101-113). Cambridge University Press. https://doi.org/10.1017/CBO9781139165860.009

Williamson, Timothy (2000). Knowledge and its Limits. Oxford University Press.

Zimmerman, Michael (2014). Ignorance and Moral Obligation. Oxford University Press. https://doi.org/10.1093/acprof:0so/9780199688852.001.0001 